\title{
Sensitivity Analysis of the Smart City Environmental Sustainability Index (SCESI)
}

\author{
Shruti†, P. K. Singh and A. Ohri \\ Department of Civil Engineering, Indian Institute of Technology, BHU, Varanasi-221005, Uttar Pradesh, India \\ $\dagger$ Corresponding author: Shruti; drshrutisingh984@gmail.com
}

Nat. Env. \& Poll. Tech.

Website: www.neptjournal.com

Received: 26-06-2020

Revised: $05-08-2020$

Accepted: $27-08-2020$

\section{Key Words:}

Environmental indicators

Sensitivity analysis

Smart city environmental

sustainability index

\begin{abstract}
In recent years, the field of Sustainable Smart Cities is rapidly burgeoning, and the related research carried out is unexplored, heterogeneous, and involves a plethora of issues. In this research, the framework for the Smart City Environmental Sustainability Index (SCESI) is defined and evaluated to guide the investments and monitor the progressive environmental development of Indian cities. The index is based on 24 environmental indicators, and their corresponding significance is assessed by the expert panel. SCESI is an integrated tool on a scale of 0 to 100 , which depends upon the value of indicators and their relative weights. However, sometimes data for all the 24 environmental indicators may not be available. The present work determines the sensitivity analysis by applying certain interventions. Eight scenarios have been generated by taking various combinations of high and low weight indicators. The analysis of the study indicates that the occurrence of error is marginal in both cases of non-availability of high and low weight indicators. Thus, the sensitivity analyses critically assess the variations in the SCESI when there are uncertainties involved in the input data.
\end{abstract}

\section{INTRODUCTION}

Rapid urbanization worldwide had created sheer pressure on the urban built environment (Turner 1990). According to the United Nations, the urban population worldwide will increase by up to $60 \%$ by the year 2050 (United Nations 2014). The bloom in the urban population will give rise to significant challenges regarding unemployment, congestion, environmental pollution and social sustainability (OECD 2012). Urban population in India is expected to reach 814 million by the year 2050, making it the second most populated country in the world (Randhawa \& Kumar 2017). Due to the rapid increase in urbanisation rate the five Indian megacities Bangalore, Delhi, Mumbai, Kolkata, and Chennai will increase to 7 by 2030, with the new addition of Ahmadabad and Hyderabad (Randhawa \& Kumar 2017). The rapid urbanization and technological advancement urge to recreate and manage the cities to cope with the challenging issue of urban population explosion. Over the last decades, the rise in environmental awareness has resulted in an opportunity to reconstruct the existing cities under a new heading as Environmentally Sustainable Smart Cities (ESSC).

Ministry of Urban Development (MoUD), Government of India (GOI) launched Smart Cities Mission (SCM) in the year 2015 with an idea to model 100 cities (MoUD 2015). The mission aims to cope up with the massive urbanization challenges of the coming decades. The concept of the mission aims towards improving the quality of life by integrating technological solutions through ICT, which can be considered as sustainable development for the cities. But the mission lacks concerns towards environmental dimensions, the most crucial aspect of sustainability. Moreover, none of the programs implemented in India prior to SCM focuses on a sustainable approach (Randhawa \& Kumar 2017), thus this mission can be taken as an opportunity to develop ESSC in India.

Topical studies reveal that there is no assessment framework available to inter-relate sustainability and smartness quotient, and the measurement methodologies to measure both strands for a particular city. Thus, a framework for ESSC has been designed using 24 indicators (Singh et al. 2020). The developed Smart City Environmental Sustainability Index (SCESI) combines the design concepts of sustainability with smartness to evaluate their practicality performance. However, city managers and policymakers may face difficulty in collecting data of all 24 indicators included in SCESI. Hence sensitivity analysis is carried out to investigate the variation of SCESI result to the variation of input data. It is carried out to enhance the reliability of the developed index by evaluating the scenarios generated due to the unavailability of data generation.

\section{CONCEPT OF SMART CITY ENVIRONMENTAL SUSTAINABILITY INDEX (SCESI)}

Smart City Environmental Sustainability Index (SCESI) has 
been developed by selecting 24 environmental indicators divided into four domains Solid Waste Management (SWM), Water Supply Management (WSM), Sewerage, Sanitation and Storm water Management (SSS) and Ambient Environment Condition (AEC). The index developed involves four steps: i. Selection of Indicators for Environmentally Sustainable Smart Cities, ii. Benchmarking of selected indicators, iii. Assigning weights for the indicators, and iv. Calculation of Smart City Environmental Sustainability Index (SCESI). The four steps used in the index formulation are briefly described here.

The first stage is the most crucial as the selection of appropriate indicators will guide the policymakers in performance assessment, monitoring and target-setting (Huovila et al. 2019). For the said purpose, Singh et al. (2020) selected
14 indicators from MoUD guidelines and 24 additional indicators through a literature survey. Further, these two groups of indicators were tested on the sustainability criteria given by World Bank (Segnestam 2002). The indicators qualified were further tested on smartness criteria given by City Key Indicators (Bosch et al. 2017). Finally, 24 indicators were selected under four broad environmental factors: Solid Waste Management (SWM), Water Supply Management (WSM), Sewerage, Sanitation and Storm Water Drainage (SSS) and Ambient Environment Conditions (AEC) which serve the purpose of ESSC (Singh et al. 2020). The second stage is allocating weights according to the relative importance of each indicator. Equal weighting approach is used for the environmental domains and Delphi methodology is carried out for assigning weight to the indicators under the same

Table 1: Selected indicator and their corresponding weights.

\begin{tabular}{|c|c|c|}
\hline Indicators & Weights $\left(\mathrm{W}_{\mathrm{k}}\right)$ & $\begin{array}{l}\text { Indicator Score } \mathrm{IS}_{\mathrm{k}}=\left(\mathrm{w}_{\mathrm{k}} \cdot \mathrm{x}_{\mathrm{k}}\right) \\
\text { (Indicator Score Code) }\end{array}$ \\
\hline \multicolumn{3}{|l|}{ A. Solid Waste Management (SWM) } \\
\hline 1. Efficiency in the collection of MSW (EC) & 0.155 & ECS \\
\hline 2. Degree of Segregation (DS) & 0.171 & DSS \\
\hline 3. Extent of solid waste recovered (SWR) & 0.163 & SWRS \\
\hline 4. Degree of scientific disposal of MSW (SD) & 0.165 & SDS \\
\hline 5. Recycling and reduction of construction and demolition waste (RCD) & 0.133 & RCDS \\
\hline 6. Extent of cost recovery in Solid Waste Management $\left(\mathrm{CR}_{\mathrm{SWM}}\right)$ & 0.130 & $\mathrm{CR}_{\mathrm{SWM}} \mathrm{S}$ \\
\hline 7. Solid Waste Management programs carried in the city during the last 3 years (SWMP) & 0.083 & SWMPS \\
\hline Total & 1.000 & SWMI $=\Sigma($ IS $)$ \\
\hline \multicolumn{3}{|l|}{ B. Water Supply Management (WSM) } \\
\hline 8. Adequacy of Water Supply (AW) & 0.151 & AWS \\
\hline 9. Smart meters and Management (SMM) & 0.145 & SMMS \\
\hline 10.Leakage identification (LI) & 0.138 & LIS \\
\hline 11.Continuity of water supplied in terms of average no of hrs per day $(\mathrm{CW})$ & 0.127 & CWS \\
\hline 12. Water Quality Monitoring (WQ) & 0.167 & WQS \\
\hline 13. Exploitation of underground water $\left(\mathrm{E}_{\mathrm{UG}} \mathrm{W}\right)$ & 0.163 & $\mathrm{E}_{\mathrm{UG}} \mathrm{WS}$ \\
\hline 14. Extent of cost recovery in water supply services $\left(\mathrm{CR}_{\mathrm{WS}}\right)$ & 0.109 & $\mathrm{CR}_{\mathrm{WS}} \mathrm{S}$ \\
\hline Total & 1.000 & WSMI $=\Sigma($ IS $)$ \\
\hline \multicolumn{3}{|l|}{ C. Sewerage, Sanitation and Storm water Management (SSS) } \\
\hline 15.Collection efficiency of Sewage Network (CE) & 0.156 & CES \\
\hline 16. Adequacy of sewage treatment capacity (AS) & 0.149 & ASS \\
\hline 17.Quality of treated sewage (QTS) & 0.152 & QTSS \\
\hline 18. Waste water recycling(WWR) & 0.148 & WWRS \\
\hline 19. Extent of Cost Recovery $\left(\mathrm{CR}_{\mathrm{SSS}}\right)$ & 0.101 & $\mathrm{CR}_{\mathrm{SSS}} \mathrm{S}$ \\
\hline 20.Coverage of toilets (CT) & 0.160 & CTS \\
\hline 21.Coverage of Storm Water Drainage (CSWD) & 0.134 & CSWDS \\
\hline Total & 1.000 & SSSI $=\sum\left(\mathbf{I S}_{\mathbf{k}}\right)$ \\
\hline \multicolumn{3}{|l|}{ D. Ambient Environment Condition (AEC) } \\
\hline 22. Ambient Air Quality (AAQ) & 0.376 & AAQS \\
\hline 23. Ambient Sound Level (ASL) & 0.325 & ASLS \\
\hline 24.Ambient Surface Water Quality (ASW) & 0.299 & ASWS \\
\hline Total & 1.000 & AECI $=\Sigma\left(\mathbf{I S}_{\mathbf{k}}\right)$ \\
\hline
\end{tabular}


domain. A survey among 30 experts comprising of researchers, policymakers, and academicians were conducted who gave the score on the scale of 1 (Least important) to 5 (Most important) to indicators under the same domain. Then Delphi analysis was carried out and weights were allocated to each indicator. For more precision, the number of experts can be increased. The 24 selected weights and their corresponding weights are shown in Table 1.

The third stage involves benchmarking each of the 24 indicators for quality standards on a scale of 0 to 100 (Poor, Average, Good, and Excellent). This will help the policymakers to ascertain gaps and perform the best remedial measures for improvement in the city. The scale range of benchmarking for each indicator is taken from the data-book of Service Level in the urban water and sanitation sector (MoUD 2012). The fourth and final stage is the calculation of the index with the help of selected indicators. This index is unidirectional with increasing value on the scale of 100 $(<20=$ Critically low; $20-40=$ Poor; $40-60=$ Fair; $60-80=$ Good; $>80$ = Excellent).

\section{Variable Aggregation}

Smart City Environmental Sustainability Index (SCESI) is the summation of the domain indices: Solid Waste Management Index (SWMI), Water Supply Management Index (WSMI), Sewerage, Sanitation and Stormwater Management Index (SSSI) and Ambient Environment Condition Index (AECI). Individual domains are the summation of indicator score eq. (1) which is calculated using weighted sum linear aggregation eq. (2). To bring uniformity, SCESI is divided by the number of environmental domains and computed using eq. (3).

$$
\mathrm{DI}=\sum_{j=1}^{n} \mathrm{ISj},
$$

Where, DI is the respective Domain Index, $\mathrm{j}$ is the serial number of Indicator, $\mathrm{n}$ is the number of indicators in the chosen domain and $\mathrm{IS}_{\mathrm{j}}$ is the Indicator Score of $\mathrm{j}^{\text {th }}$ indicator

$$
\mathrm{IS}_{\mathrm{k}}=\left(\mathrm{w}_{\mathrm{k}} \cdot \mathrm{x}_{\mathrm{k}}\right) \text {, }
$$

Where, $\mathrm{w}$ is the weight of the indicator, $\mathrm{x}$ is the benchmarked indicator Value and $\mathrm{k}$ is the identification number of a chosen indicator.

$$
\mathrm{SCESI}=(\mathrm{SWMI}+\mathrm{WSMI}+\mathrm{SSSI}+\mathrm{AECI}) / 4
$$

When the data is not available for all the 24 environmental indicators included in environmental domains, then the domain index is calculated using eq. (4). Summation of normalised domain indices $\left(\mathrm{DI}_{\mathrm{m}}\right)$ gives the normalised Smart City Environmental Sustainability Index ( $\left.\mathrm{SCESI}_{\mathrm{m}}\right)$.

$$
D I=\frac{\sum_{j=1}^{n} I S j}{\sum_{i=1}^{n} W i}
$$

Where, $\mathrm{W}_{\mathrm{i}}$ is the summation of the weights given by experts to the indicators in each domain; $\mathrm{W}_{\mathrm{i}} \leq 1$.

Non-availability of data can cause an error in the calculation of SCESI which can be calculated by using eq. (5).

$$
\text { PercentageError }=\frac{\text { SCESIm-SCESI }}{\text { SCESI }}
$$

\section{AIM OF THE RESEARCH}

In the present research, Sensitivity Analysis is carried out for the index developed known as Smart City Environmental Sustainability Index (SCESI). Sensitivity Analysis investigates the variation in output factor when there is a variation in input factors (Pianosi et al. 2016). SCESI developed depends on the weight given by experts and data generated for each indicator. It is justified to assume that data gathered by municipalities or reliable sources is not flawless, and some percentage of error may be expected (Saisana \& Saltelli 2008). Moreover, non-availability of data for all the 24 environmental indicators may be possible, which affects the overall index result. Hence, sensitivity analysis is carried out by generating eight scenarios. The result of the analysis can address a wide range of questions like which indicator has the highest dependency, lowest dependency or negligible effect on the SCESI. The methodology adopted for Sensitivity Analysis is discussed in the further section.

\section{MATERIALS AND METHODS}

To assess the uncertainties involved due to the non-availability of the data, case study of five Indian cities: Delhi (D), Patna (P), Varanasi (V), Allahabad (A) and Bhubaneswar (B) is taken up. The sources of data for Solid Waste Management, Water Supply Management and Sewerage, Sanitation and Stormwater Management are City Development Plan (CDP) and Swachh Sarvechhan Report (SSR) from the Swachh Bharat Mission program. Ambient Environment condition data is obtained through the Central Pollution Control Board (CPCB) and ENVIS website of respective cities. To avoid discrepancy in the result a factor of 0.25 is taken for indicator having a critically low performance. To estimate the errors involved in calculating the Smart City Environmental Sustainability Index, due to the non-availability of indicator data, an approach of Ignoring indicator data based on weight factor is used (Kumar \& Alappat 2005, Ohri \& Singh 2011). Further, in this approach, two options are explored. In the first option, the data of the environmental indicator having high weight in each of the four domains are ignored and in the second option, the data of the environmental indicator having low weight in all the four domain data are assumed 
to be unavailable. The results obtained in the two options are discussed further.

\section{Removing Indicators with High Weight Factor}

1. In the first step, the Domain indices are calculated using 7 indicators (7I) for SWMI, 7 indicators (7I) for WSMI, 7 indicators for SSSI (7I) and 3 indicators for AECI (3I). Respective Domain Indices is calculated using eq. (1) and (2).

2. In the second step, the indicator having the highest weight in each domain is presumed to be unknown. For calculating domain indices, 6 indicators (6I) for SWMI, 6 indicators (6I) for WSMI, 6 indicators for SSSI (6I) and 2 indicators for AECI (2I) is involved. Degree of Segregation (0.171) in SWM, Water Quality Monitoring (0.167) in WSM, Coverage of toilets (0.160) in SSS and Ambient Air Quality (0.376) in AEC is ignored (Table 2). As the data of indicator having the highest weight is presumed to be unknown the domain indices are calculated using eq. (4).

3. In the third step, it is presumed that indicators having the second-highest weight are unavailable along with the indicators involved in step 2. For calculating domain indices, 5 indicators (5I) for SWMI, 5 indicators (5I) for WSMI, 5 indicators for SSSI (5I) and 2 indicators for AECI (2I) is taken up. Degree of scientific disposal of MSW (0.165) in SWM, Exploitation of underground water (0.163) in WSM and Collection efficiency of Sewage Network (0.156) in SSS is ignored (Table 2). Respective domain indices are calculated using eq. (4).

4. The percentage error occurred due to calculating domain index value with respect to the domain index value when data for all the indicators are available is also reported in the last row (Table 2).

\section{Removing Indicators with Low Weight Factor}

1. In the first step, the Domain indices are calculated using 7 indicators (7I) for SWMI, 7 indicators (7I) for WSMI, 7 indicators for SSSI (7I) and 3 indicators for AECI (3I). Respective Domain Indices is calculated using eqns. 1 and 2.

2. In the second step, the indicator having the lowest weight in each domain is presumed to be unknown. For calculating domain indices, 6 indicators (6I) for SWMI, 6 indicators (6I) for WSMI, 6 indicators for SSSI (6I) and 2 indicators for AECI (2I) is involved. Solid Waste Management programs carried in the city during the last 3 years (0.083) in SWM, Extent of cost recovery in water supply services (0.109) in WSM, Extent of Cost
Recovery (0.101) in SSS and Ambient Surface Water Quality (0.299) in AEC is ignored (Table 3). As the data of indicator having the lowest weight is presumed to be unknown the domain indices are calculated using eq. (4).

3. In the third step, it is presumed that the second-lowest weight indicators are unavailable along with the indicators involved in step 2. For calculating domain indices, 5 indicators (5I) for SWMI, 5 indicators (5I) for WSMI, 5 indicators for SSSI (5I) and 2 indicators for AECI (2I) is taken up. Extent of cost recovery in Solid Waste Management (0.130) in SWM, Continuity of water supplied in terms of average no of hrs per day (0.127) in WSM and Coverage of Storm Water Drainage (0.134) in SSS is ignored (Table 3). Respective domain indices are calculated using eq. (4).

4. The percentage error occurred due to calculating domain index value with respect to the domain index value when data for all the indicators are available is also reported in the last row (Table 3).

\section{RESULTS AND DISCUSSION}

The precision of the outcome is determined by sensitivity analysis when certain interventions are applied (Sözer \& Takmaz 2020). Each intervention has a different impact on the overall index developed. Eight scenarios have been generated in high and low weight factors respectively. The different combinations involved in eight scenarios are as follows: 7 indicators of SWM, 7 indicators of WSM, 7 indicators of SSS, 3 indicators of AEC (Total=24); 6 indicators of SWM, 7 indicators of WSM, 7 indicators of SSS, 3 indicators of AEC (Total 23); 5 indicators of SWM, 7 indicators of WSM, 7 indicators of SSS, 3 indicators of AEC (Total 22); 5 indicators of SWM, 6 indicators of WSM, 7 indicators of SSS, 3 indicators of AEC (Total 21); 5 indicators of SWM, 5 indicators of WSM, 7 indicators of SSS, 3 indicators of AEC (Total 20); 5 indicators of SWM, 5 indicators of WSM, 6 indicators of SSS, 3 indicators of AEC (Total 19); 5 indicators of SWM, 5 indicators of WSM, 5 indicators of SSS, 3 indicators of AEC (Total 18); 5 indicators of SWM, 5 indicators of WSM, 5 indicators of SSS, 2 indicators of AEC (Total 17).

Normalised SCESI is calculated by summing up the normalised domain indices values. Percentage error is calculated using eqn 5 . The result of the analysis is shown in Fig. 1 and Fig. 2. The highest error of $8.8 \%$ is introduced when 2 indicators of high weight indicators are ignored in the city Bhubaneswar. A marginal error upto 5\% is reported in the other cities. An error of $12.95 \%$ is reported in the city Delhi when 7 indicators of low weight factor are ignored. An assessment of the result shows that the error involved in 


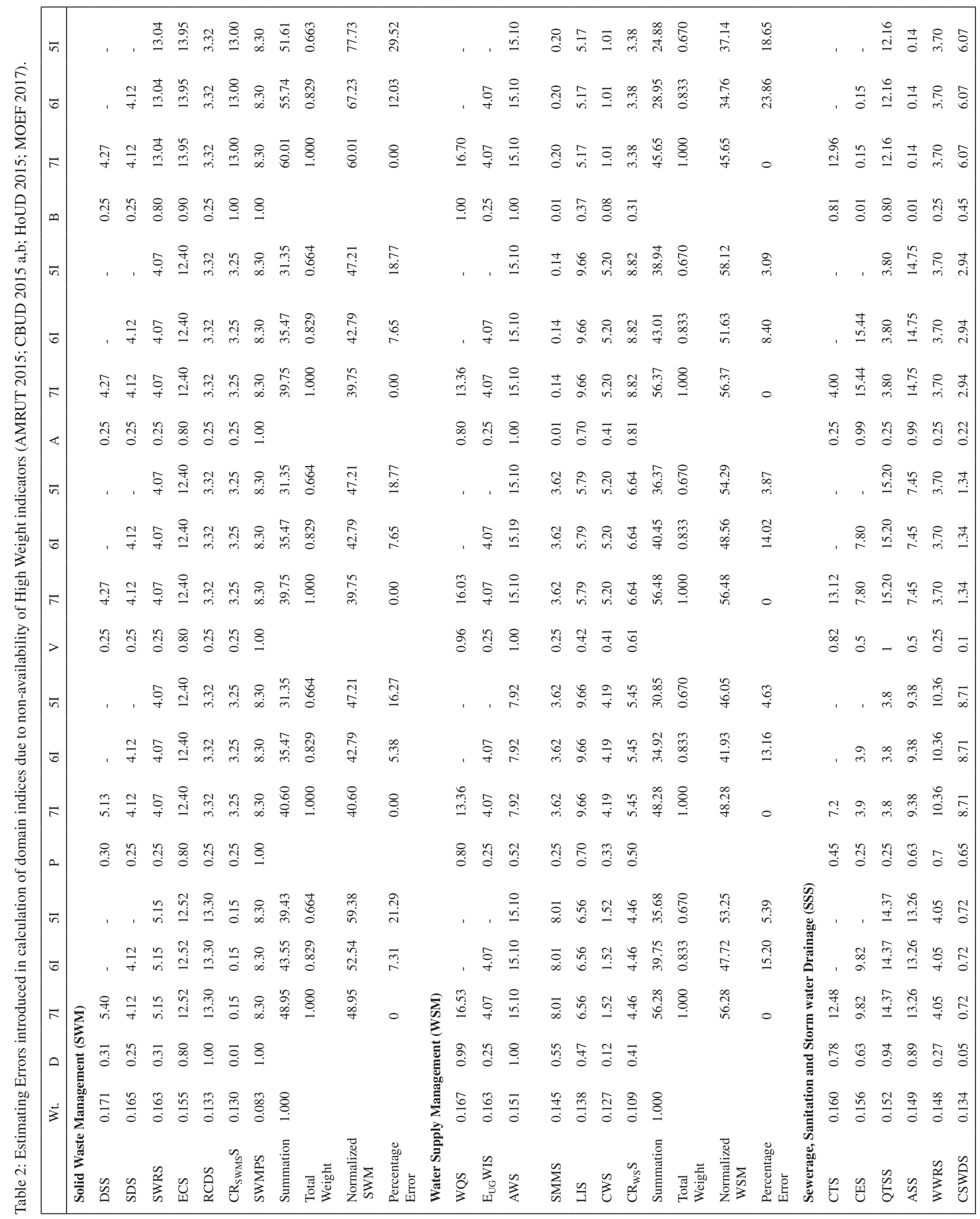




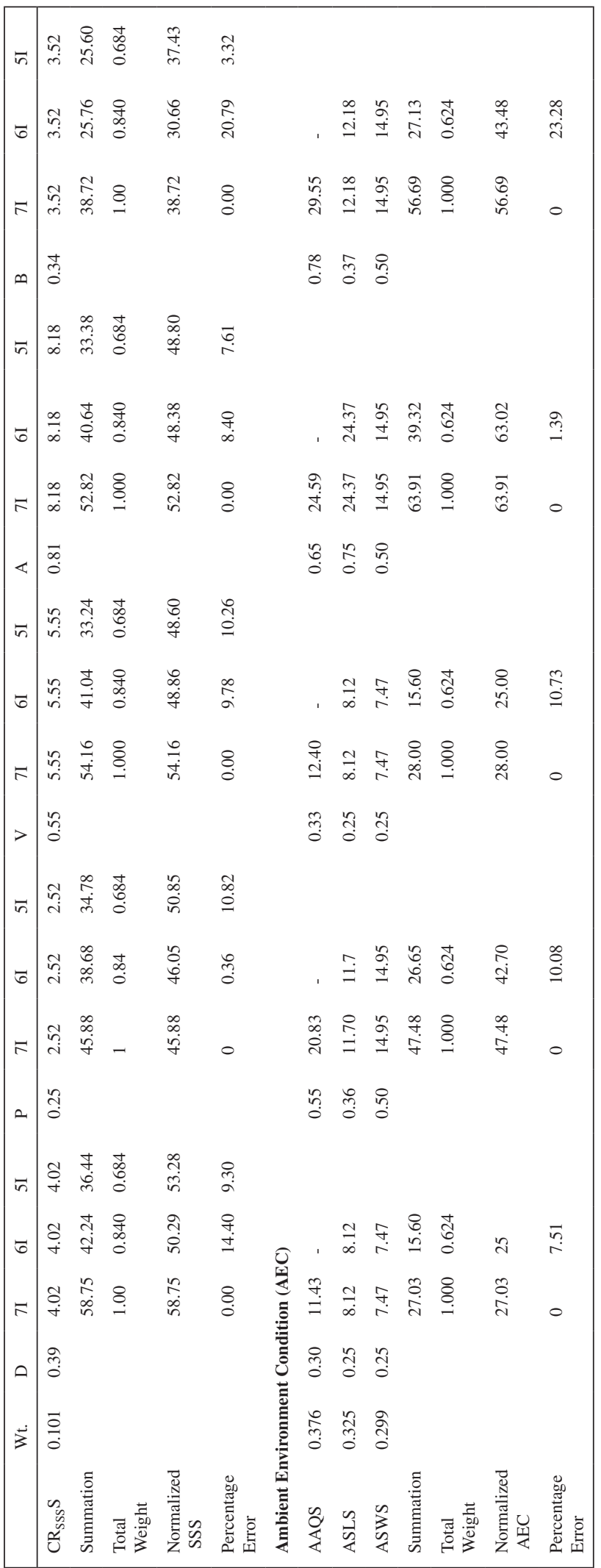

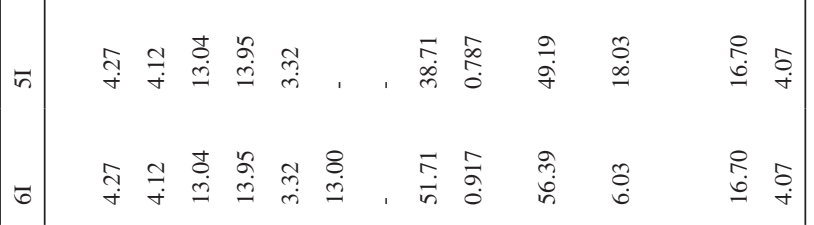

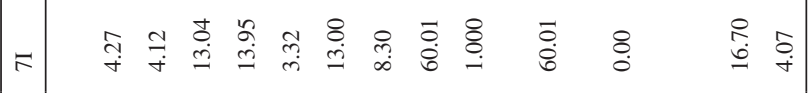

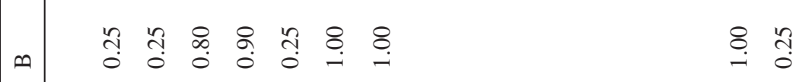

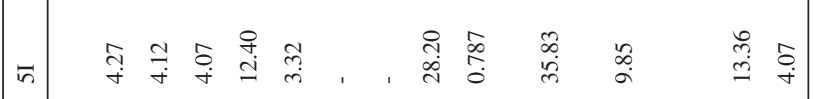

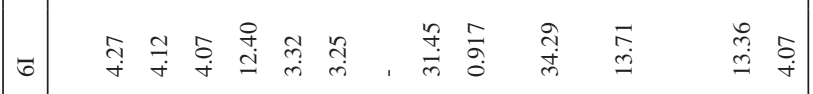

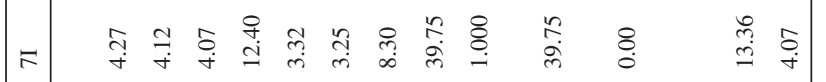

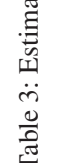

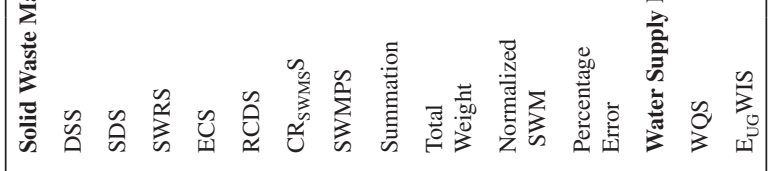




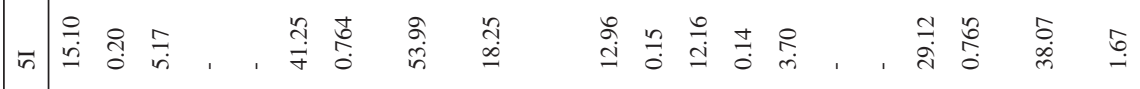

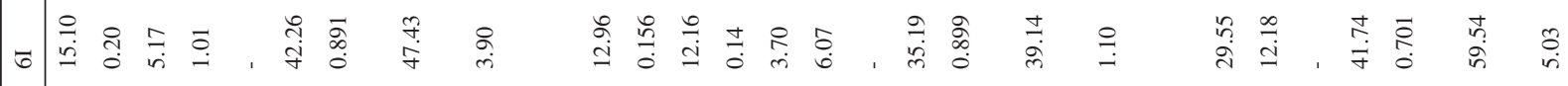

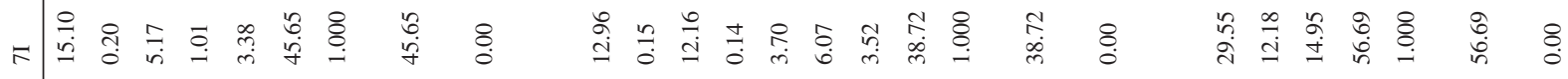

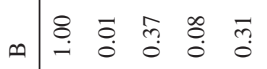

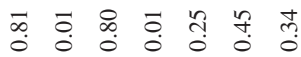

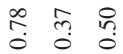

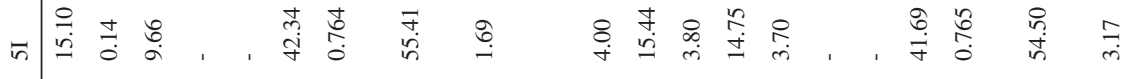

-

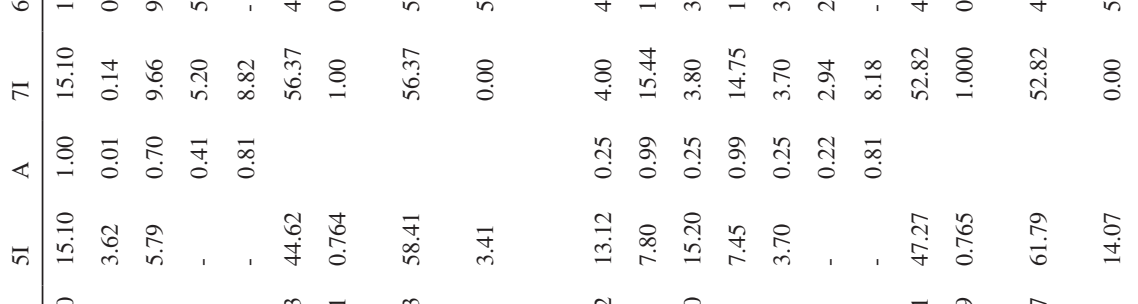

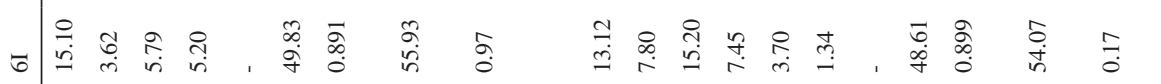

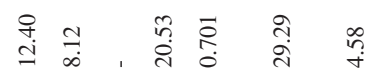

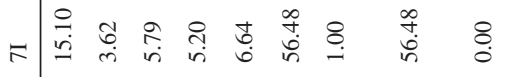

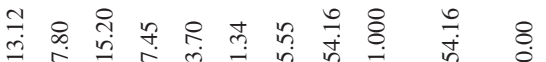

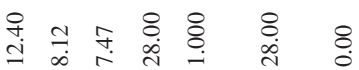

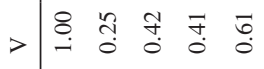

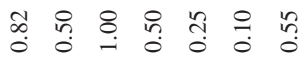

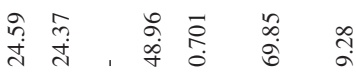

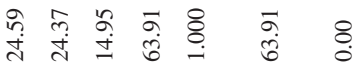

ㄴ.

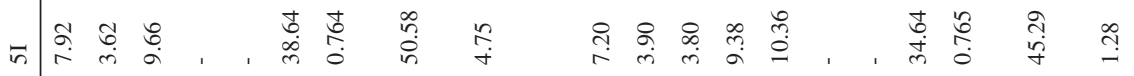

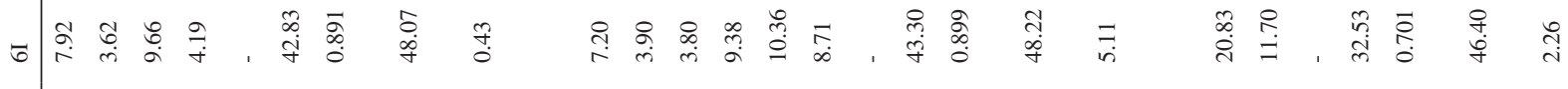

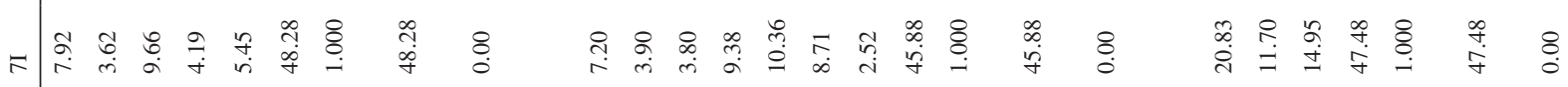

2 म

in

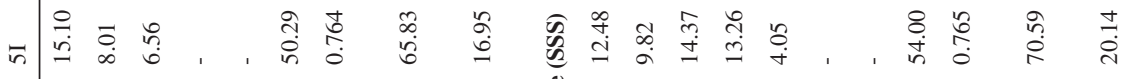

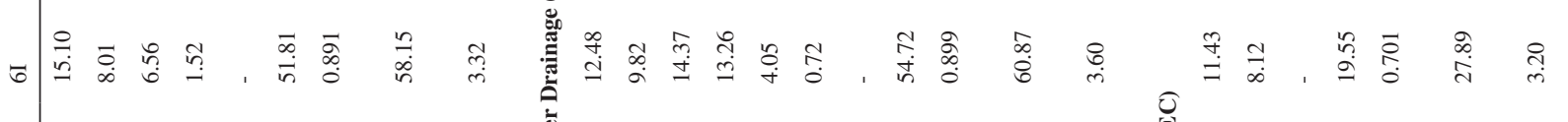

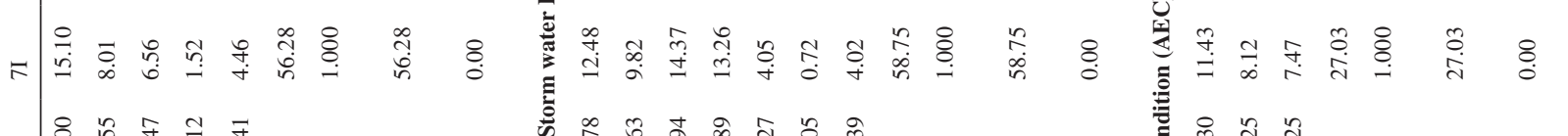

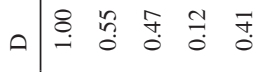

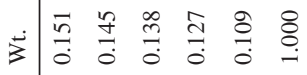

总

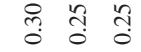

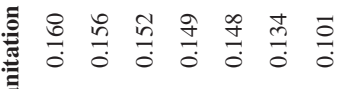

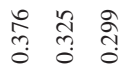

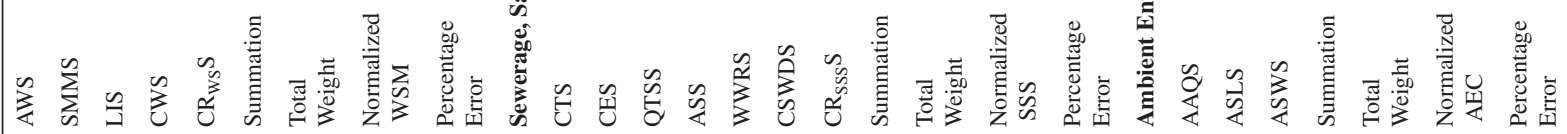




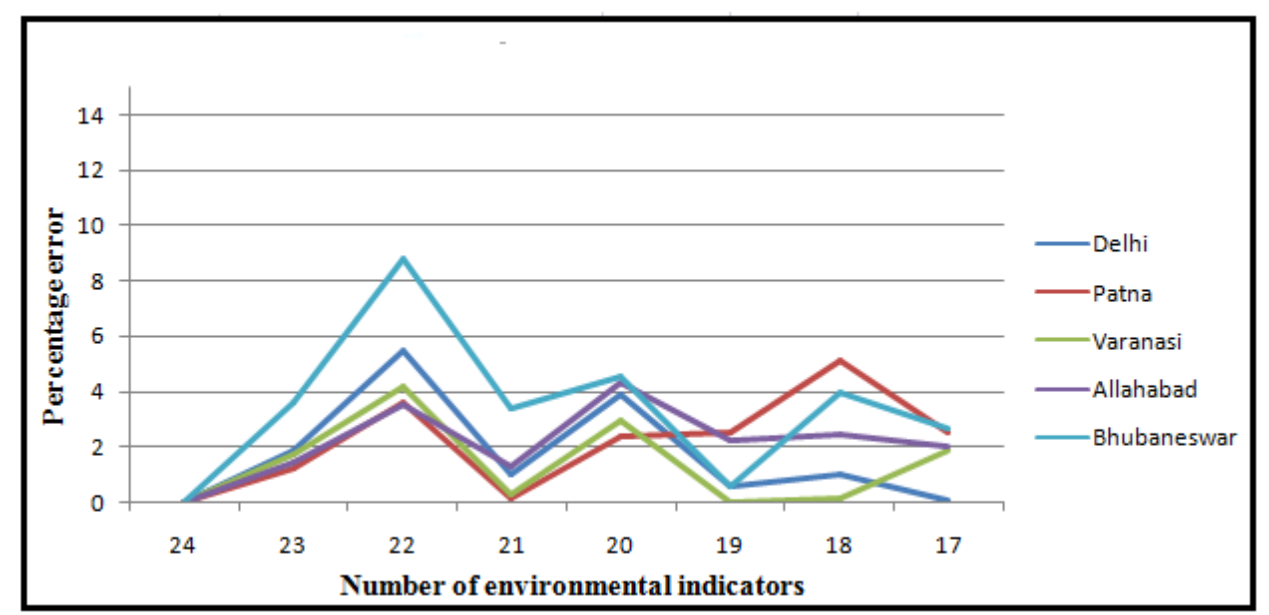

Fig. 1: Variation of percentage error in SCESI with decreasing number of indicators due to non-availability of high weight parameters.

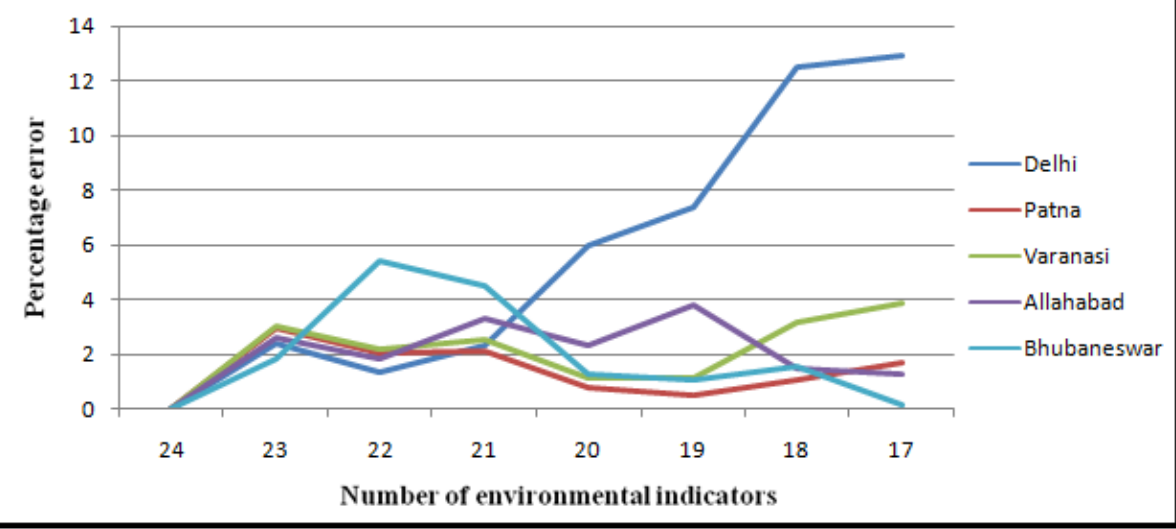

Fig. 2: Variation of percentage error in SCESI with decreasing number of indicators due to non-availability of Low weight parameters.

the different scenarios is not significantly dependent on the number of environmental indicators considered, for which data is unavailable.

\section{CONCLUSIONS}

Smart City Environmental Sustainability Index (SCESI) is calculated on the basis of 24 environmental indicators and their corresponding weights. Due to resource and time constraint, unavailability of data is a general phenomenon. For this purpose sensitivity analysis is carried out to explore the possible sets of missing data set. A classification of indicators in high and low weight categories has been done to show its effect on SCESI, in case of non-availability of data. Eight scenarios have been generated, which showed that percentage error is highest when 7 indicators of low weight category are ignored. A marginal error up to $12 \%$ is introduced if there is non-availability of high or low weights indicators. Thus, SCESI can be reported with a marginal error but the policymakers should prioritize the efforts for data collection to be non-biased towards the development of Environmentally Sustainable Smart Cities.

\section{REFERENCES}

AMRUT, 2015. Bihar State Annual Action Plan for proposed schemes under AMRUT. Available from http://amrut.gov.in/upload/uploadfiles/ files/19\%20BiharSAAP.pdf.

Bosch, P., Jongeneel, S., Rovers, V., Neumann, H.M., Airaksinen, M. and Huovila, A. 2017. CITYkeys Indicators for smart city projects and smart cities. CITYkeys report.

CBUD 2015a. City Development Plan for Allahabad, 2041 (Final City Development Plan). Available from http://allahabadmc.gov.in/ documentslist/City_Development_Plan_Allahabad-2041.pdf.

CBUD 2015b. City Development Plan for Varanasi, 2041 (Final City Development Plan). Available from http://nnvns.org/data/Final\%20 CDP\%20Varanasi.pdf. 
HoUD 2015. Declaration of Service Standards. Available from http:// www.urbanodisha.gov.in/Admin/Upload_Files/Service\%20Leve1\%20 Benchmark/SLB\%202014-15-\%20\%202015-16.pdf.

Huovila, A., Bosch, P. and Airaksinen, M. 2019. Comparative analysis of standardized indicators for Smart sustainable cities: What indicators and standards to use and when? Cities, 89: 141-153.

Kumar, D. and Alappat, B.J. 2005. Errors involved in the estimation of leachate pollution index. Pract. Period. Hazard. Toxic Radioact. Waste Manage., 2: 103-111.

MoEF 2017. Air and noise pollution in Delhi and NCR.

MoUD 2012. Service levels in Urban water and sanitation sector Status Report (2010-2011). Ministry of Urban Development, Government of India.

MoUD 2015. Mission statements and Guidelines. Available from http:// smartcities.gov.in/upload/uploadfiles/files/SmartCityGuidelines(1).pdf.

OECD 2012. Environmental outlook to 2050. The consequences of inaction [cited 23 February 2016]. Availablefromhttp://www.naturvardsverket. se/upload/miljoarbeteisamhallet/internationelltmiljoarbete/ multilateralt/oecd/outolook-2050-oecd.pdf.

Ohri, A. and Singh, P.K. 2011. Error involved in estimation of site sensitivity index (SSI) for landfilling of municipal solid waste. Int. J. Environ. Sci., 1: 767-770

Pianosi, F., Beven, K., Freer, J., Hall, J.W., Rougier, J., Stephenson, D.B. and Wagener, T. 2016. Sensitivity analysis of environmental models: A systematic review with practical workflow. Environ. Modell. Softw., 79: 214-232.

Randhawa, A. and Kumar, A. 2017. Exploring sustainability of smart development initiatives in India. Int. J. Sustain. Built. Environ., 6: 701-710.

Saisana, M. and Saltelli, A. 2008. Sensitivity Analysis for the 2008 Environmental Performance Index. European Commission: Fermi.

Segnestam, L. 2002. Indicators of Environment and Sustainable Development, (No. P01 234). World Bank, Washington, DC (EUA).

Singh, P.K., Shruti and Ohri, A. 2020. selecting environmental indicators for sustainable smart cities mission in India. Nat. environ. Pollut. Technol., 19: 201-210.

Sözer, H. and Takmaz, D. 2020. Calculation of the sensitivity factors within the defined indexes in a building level. J. Sustain. Dev. Energy Water Environ. Syst., 1: 1-21.

Turner, B.L. 1990. The earth as transformed by human action: global and regional changes in the biosphere over the past 300 years: CUP archive. United Nations, 2014. World urbanization prospects. The 2014 revision. New York: Department of Economic and Social Affairs [cited 22 May 2016]. Available from http://esa.un.org/unpd/wup/Publications/Files/ WUP2014-Report.pdf. 